\title{
Dependence of the pullout behaviour of pedicle screws on the screw-hosting material relative deformability
}

Article in International Journal of Computer Aided Engineering and Technology • January 2013

DOI: 10.1504/IJCAET.2013.056701

CITATIONS

2

4 authors, including:

Panagiotis Chatzistergos

Staffordshire University

53 PUBLICATIONS 113 CITATIONS

SEE PROFILE

Stavros Kourkoulis

National Technical University of Athens

134 PUBLICATIONS 570 CITATIONS

SEE PROFILE
READS

18
Evangelos A Magnissalis

39 PUBLICATIONS 231 CITATIONS

SEE PROFILE

Some of the authors of this publication are also working on these related projects:

DiaBSmart: Development of a new generation of DIABetic footwear using an integrated approach and SMART materials View project 
Title: Dependence of the pullout behaviour of pedicle screws on the screw hosting material relative deformability

\begin{abstract}
:
Indications exist in literature that a screw's pullout behaviour is among others influenced by the relative deformability of the screw and its hosting material. In addition it is known that the stress field developed in the vicinity of an orthopaedic implant significantly influences bone remodelling. In this context an experimentally validated finite element model of a screw and its hosting material was employed for the study of the pullout phenomenon. The results indicated that the stress distribution within the screw's hosting material is strongly influenced by the ratio of the screw's elastic modulus over the respective one of its hosting material. In addition it is concluded that an optimum value of this ratio exists for which the stresses are more uniformly distributed along the length of the screw improving this way the pullout behaviour, and therefore the overall mechanical response, of the "screw-hosting material" complex.
\end{abstract}

Copyright $@ 200 x$ Inderscience Enterprises Ltd. 


\section{Text:}

\section{Introduction}

Pedicle screws, namely implantable screws inserted into a vertebra through its pedicle, have become some of the most commonly used instrumentation for spine stabilization. In clinical practice they are combined with rods and plates to connect and fix together neighbouring vertebrae. From a purely engineering point of view their role is to maintain the rigidity of the spinal fixation system by gripping rigidly into the stabilized vertebrae and withstanding significant bending moments. Despite the advances achieved during the last decades in the fields of medical device design and manufacturing, implant failures of pedicle screw fixation still occur. The most common complications include screw bending, breaking and loosening (Okuda et al., 2006).

According to international experimental standards (ASTM-F543-02) the fixation strength of a bone screw can be quantified by its pullout force, namely the co-axial force necessary to pull the screw out of its hosting material.

According to the literature the pullout force of a screw is influenced strongly by the properties of its hosting material (Zindrick et al., 1986, Reitman et al., 2004, Koranyi et al., 1970, Chapman et al., 1996). Existing experimental studies indicate that a screw's pullout force increases linearly with increasing 
shear strength of its hosting material (Chapman et al., 1996). The fixation strength of a screw is also influenced by the design of the screw (Krenn et al., 2008, Inceoglu et al., 2008, Gefen, 2002, Chatzistergos et al., 2010a) and the insertion technique used by the surgeon (Conrad et al., 2005, Chatzistergos et al., 2010b).

There are also indications that the mechanical behaviour of a screw is influenced by the difference between the screw stiffness and the respective stiffness of the screw's hosting material (Kourkoulis et al., 2008, Tafreshi and Dover, 1993, Zhang et al., 2004, Zhang et al., 2006, Chatzistergos et al., 2010a). In a previous combined numerical and experimental investigation (Chatzistergos et al., 2010a) performed by the authors of the present study it was concluded that: when a metallic screw is pulled from a solid rigid polyurethane foam (SRPF) block (with material properties similar to these of osteoporotic bone), most of the load is carried by the threads most distant from the free surface. On the contrary a numerical analysis of the mechanical behaviour of threaded connections between metallic parts indicated that most of the pullout load is carried by the threads closest to the free surface (Tafreshi and Dover, 1993). A similar conclusion was also drawn from an experimental study on the pullout behaviour of threaded anchors in marble (Kourkoulis et al., 2008). 
The different pullout behaviour of the "screw - hosting material" complex observed in the context of the aforementioned studies could be attributed to the different relative deformability of the screw's material compared to its hosting material.

It should be stressed out that in the case of orthopaedic implants (such as the bone screws) their in-situ ability to uniformly distribute applied loads can influence significantly their long term efficiency. Bone remodelling around orthopaedic implants is greatly influenced by the intensity and the uniformity of the stress field in the vicinity of the implant (Gefen, 2002, Van Rietbergen et al., 1993).

In this context the present study aims at investigating the impact of the screw and hosting material relative deformability on the pullout behaviour of the "screw - hosting material" complex. For this purpose a finite element (FE) model which was initially designed and validated for simulating the pullout of a rigid screw from a SRPF block simulating osteoporotic bone (Chatzistergos et al., 2010a) is here modified and re-validated to be used in cases where the screw and its hosting material are of comparable stiffness. The modified FE model's accuracy is validated against experimental data obtained in the framework of the present study. 


\section{Mechanical testing}

\section{$2.1 \quad$ Materials and methods}

The mechanical tests were performed using blocks of synthetic bone (Sawbones, Worldwide, Pacific Research Laboratories Inc.) in strict accordance to the ASTM-F543-02 standard. More specifically cubic blocks of synthetic bone were fixed to the base of the loading frame (MTS Insight 10kN, MTS Systems Corp., Eden Prairie, MN) with the aid of a metallic frame while the screw was suspended from the load cell (MTS 662.20D-04 Axial/Torsional Load Transducer) using a custom-made device (Figure 1). The displacement was imposed to the screw in the pullout direction at a constant rate equal to 0.01 $\mathrm{mm} / \mathrm{s}$ while the respective force was measured with a sampling rate of $10 \mathrm{~Hz}$.

The initial FE model for the simulation of the pullout phenomenon was validated against experimental data for three commercially available pedicle screws, namely for the CDH7.5, CDH6.5 (Medtronic Sofamor Danek, Memphis, TN) and TL-Java5 (Zimmer Spine, Bordeaux, France) screws inserted into solid rigid polyurethane foam (SRPF) blocks of density equal to $0.16 \mathrm{gr} / \mathrm{cm}^{3}$ and material properties similar to osteoporotic bone (Chatzistergos et al., 2010a). In 
the context of the present study additional pullout tests were performed for the CDH6.5 and CDH7.5 screws (Figure 2) inserted into a much more compact SRPF of density equal to $0.48 \mathrm{gr} / \mathrm{cm}^{3}$. The experimental data obtained were utilized to validate a modified version of the aforementioned FE model for SRPFs of varying density.

Each test was repeated six times to estimate the mean value and standard deviation of the pullout force for the $\mathrm{CDH7.5}$ and CDH6.5 pedicle screws. The material properties of the SRPFs used for the purposes of the present experimental study as well as those of a typical Ti-alloy used for medical device manufacturing (Long and Rack, 1998) are showed in detail in table 1.

For the insertion of the screws into the SRPF blocks, guiding holes (35 mm deep) were drilled using a drill press and then tapped manually using taps provided by the manufacturer (Chatzistergos et al., 2010b, Chatzistergos et al., 2010a). Finally the screws were inserted $25 \mathrm{~mm}$ deep into the threaded holes.

\subsection{Results}

The pullout tests indicated that when a cylindrical pedicle screw is pulled out of a SRPF block of density equal to $0.48 \mathrm{gr} / \mathrm{cm}^{3}$, the synthetic bone which lies in the vicinity of the screw fails under shear. As it can be seen in figure 3 the failure 
occurs on a cylindrical surface connecting the edges of the threaded hole inside the SRPF. The pullout force for the CDH7.5 and the CDH6.5 screw was measured to be $2443 \pm 10 \mathrm{~N}$ and $2338 \pm 63 \mathrm{~N}$ respectively.

\section{3. $\quad$ Finite element analysis}

The current numerical analysis aims at investigating the impact of screw and hosting material properties on their mechanical behaviour when they are subjected to pure pullout loads. For this purpose a previously designed and validated FE model simulating the pullout phenomenon was properly modified and utilized.

\subsection{Model design}

In the context of a previous study (Chatzistergos et al., 2010a) the pullout phenomenon was simulated with a 2-dimensional (2D), axisymmetrical FE model designed using the ANSYS11.0 software. The pedicle screw was initially considered to be rigid. The geometry of the screw FE model is shown in figure 4, while the values of the characteristic quantities defining thread geometry are listed in table 2. On the other hand the synthetic bone was simulated as a homogenous, isotropic, linear elastic - perfectly plastic material. The geometry of 
the synthetic bone FE model is shown in figure 5. The innovation implemented into the design of this FE model was the accurate simulation of the experimentally observed failure of the synthetic bone, namely failure under shear loads. More specifically the elements of the synthetic bone which lay in the vicinity of the screw (area (i) in figure 5) were designed in a way allowing them to break apart from one another when the shear stress in their interface reached a critical value, equal to the synthetic bone's shear yield stress. The mode-II debonding of neighbouring elements was controlled with a bilinear cohesive zone material model (ANSYS, Alfano and Crisfield, 2001).

This initial FE model was validated against experimental data obtained from pullout tests performed on SRPF blocks simulating osteoporotic cancellous bone. The density of the SRPF used was $0.16 \mathrm{gr} / \mathrm{cm}^{3}$ and its compressive modulus of elasticity was equal to $57 \mathrm{MPa}$, namely four orders of magnitude lower than the elastic modulus of the screw's material (Table 1). Taking into consideration the large difference between the elastic moduli of the screw and its hosting material it is easily concluded that the strains developed into the screw will be negligible when compared to those developed into the synthetic bone, and therefore the screw was simulated as a perfectly rigid body. This simplification decreased the computational requirements of the model but at the same time 
restricted its application range to cases where the screw is significantly "stiffer" (in fact ideally rigid) compared to its hosting material.

For the needs of the present study the aforementioned model was modified to be applicable also in cases where the screw and its hosting material have comparable elastic moduli. This was achieved by replacing the "rigid" FE model of the screw by a suitable deformable one. Considering the difference between the failure stresses of Ti-6Al-4V alloy and SRPF the screw's material was simulated as linearly elastic with elastic modulus equal to $110 \mathrm{GPa}$ (Table 1). The model of the screw was meshed using $2-\mathrm{D}$, four - node elements (Plane182). The density of the FE mesh was optimized to avoid mesh dependency phenomena. The total number of FEs used for the model of the screw was approximately 1600 .

The model was supported and loaded in a manner consistent to the experimental procedure previously described (Figure 6) while the boundary conditions imposed at the interface between the screw and its hosting material were those of simple contact with friction (Chatzistergos et al., 2010a). 


\subsection{Validation}

The ability of the modified FE model to calculate the pullout force of cylindrical screws when the screws are pulled out from SRPF blocks of varying densities was validated against experimental data which were obtained in the context of the present study but also by utilizing data that were produced in the context of a previous one (Chatzistergos et al., 2010a). More specifically, the pullout force of the CDH7.5 and CDH6.5 screws was measured equal to $438 \pm 2 \mathrm{~N}$ and $382 \pm 3 \mathrm{~N}$ respectively (Chatzistergos et al., 2010a) when the pedicle screws were inserted into SRPF blocks of density equal to $0.16 \mathrm{gr} / \mathrm{cm}^{3}$. The respective numerically calculated values (using the here modified FE model) were $436 \mathrm{~N}$ and $381 \mathrm{~N}$.

On the other hand when the $\mathrm{CDH7.5}$ and the CDH6.5 pedicle screws were inserted into SRPF blocks of density equal to $0.48 \mathrm{gr} / \mathrm{cm}^{3}$ their pullout force was measured equal to $2443 \pm 10 \mathrm{~N}$ and $2338 \pm 63 \mathrm{~N}$ (see paragraph 2.3), while the respective numerically calculated values (using the modified FE model) were $2552 \mathrm{~N}$ and $2249 \mathrm{~N}$.

The comparison between the values of the experimentally measured and the numerically calculated pullout forces can be seen in figure 7. For the case of the low density SRPF block, the difference between experimentally measured and numerically calculated pullout force is less than $0.5 \%$, while for the case of 
the high density SRPF block the respective difference is less than $4.5 \%$. Based on the above it can be concluded that the FE model in the form used for the present study can predict with satisfactory accuracy the pullout force of cylindrical screws when these screws are inserted into SRPF blocks of varying density.

\subsection{Parametric studies}

The as above modified FE model was utilized for the completion of two parametric analyses. The first one aimed at investigating the impact of the shear yield strength of synthetic bone to the screw's pullout force while the second one at investigating the impact of the relative screw - synthetic bone stiffness to their pullout behaviour.

For the realization of the first parametric study the material properties of the screw were kept constant while the respective ones of the synthetic bone were adjusted to simulate SRPFs of different densities. SRPFs with densities ranging from $0.08 \mathrm{gr} / \mathrm{cm}^{3}$ to $0.8 \mathrm{gr} / \mathrm{cm}^{3}$ were considered in the study. According to the manufacturer (Sawbones) the compressive elastic modulus of these SRPFs ranges from $16 \mathrm{MPa}$ to $1148 \mathrm{MPa}$ while their shear yield stress ranges from 0.59 $\mathrm{MPa}$ to $16 \mathrm{MPa}$. The mechanical properties of the SRPFs included into this numerical analysis are presented in detail in table 3. 
For the realization of the second parametric study the material properties of the synthetic bone were kept constant (simulating SRPF of density $0.16 \mathrm{gr} / \mathrm{cm}^{3}$ and elastic modulus equal to $58 \mathrm{MPa}$ ) while the elastic modulus of the screw varied between broad limits. More specifically the scenarios investigated included the cases where the ratio of screw's elastic modulus over the respective one of its hosting material $\left(\mathrm{E}_{\mathrm{screw}} / \mathrm{E}_{\mathrm{hm}}\right)$ was equal to 100,10 and 1 .

\subsection{Results}

The numerical simulations performed for different values of synthetic bone density indicated that, from a qualitative point of view, the mechanical behaviour of the "screw - synthetic bone" complex remains the same for synthetic bone density varying from $0.08 \mathrm{gr} / \mathrm{cm}^{3}$ to $0.8 \mathrm{gr} / \mathrm{cm}^{3}$. A typical force/displacement curve produced for the case where the CDH7.5 screw is pulled out of a SRPF block of density equal to $0.8 \mathrm{gr} / \mathrm{cm}^{3}$ is presented in figure 8 . The respective distribution of the von Mises equivalent stress into the synthetic bone and the screw is presented in figures 9 and 10 for two different loading steps, namely for pullout displacements equal to $0.1 \mathrm{~mm}$ and $4.5 \mathrm{~mm}$ respectively. As it can be seen in figure 9 the strongest stress concentration appears in the vicinity of the thread most distant from the free surface (i.e. the deepest thread). As the loading 
increases this stress concentration is intensified causing the failure of the synthetic bone in this area. The failure of the synthetic bone can be observed in figure 10 where it is also seen that the stress field in the vicinity of the deepest threads, where failure of the synthetic bone has occurred, is relieved.

The dependence of the pullout force of the CDH7.5 and the CDH6.5 screws on the shear yield stress of their hosting material is presented in figure 11. It is seen that in both cases the pullout force increases linearly with the synthetic bone's shear yield strength.

In the aforementioned scenarios the $\mathrm{E}_{\mathrm{screw}} / \mathrm{E}_{\mathrm{hm}}$ ratios ranged from 6875 to 96. In the context of the second parametric study the material properties of the synthetic bone were kept constant (simulating SRPF of density equal to 0.16 $\mathrm{gr} / \mathrm{cm}^{3}$ ) and the elastic modulus of the screw varied resulting to $\mathrm{E}_{\mathrm{screw}} / \mathrm{E}_{\mathrm{hm}}$ ratios equal to 100,10 and 1 .

The results of this analysis indicated that the mechanical behaviour of the "screw - hosting material" complex is significantly influenced by their relative deformability. In figures 12-17 one can see the distribution of the von Mises equivalent stress developed into the synthetic bone and the respective force carried by each thread of the screw for $\mathrm{E}_{\mathrm{screw}} / \mathrm{E}_{\mathrm{hm}}$ ratios equal to 100 (figures 12,13), equal to 10 (figures 14,15) and equal to 1 (figures 16,17). Based on these 
stress distributions (figures 12,14,16) one concludes that the stress field developed in the vicinity of the less distant to the free surface threads is intensified with decreasing $\mathrm{E}_{\mathrm{screw}} / \mathrm{E}_{\mathrm{hm}}$ ratio. At the same time the stress field developed around the deepest threads becomes weaker with decreasing $\mathrm{E}_{\mathrm{screw}} / \mathrm{E}_{\mathrm{hm}}$ ratio.

Similarly the distribution of the forces carried by each thread (figures 13 , $15,17)$ indicates that, when the screw is significantly stiffer than its hosting material $\left(\mathrm{E}_{\mathrm{screw}} / \mathrm{E}_{\mathrm{hm}} \geq 100\right)$ most of the pullout force is carried by the deepest threads (figure 13). On the contrary when the screw and its hosting material have the same stiffness $\left(E_{\text {screw }} / E_{h m}=1\right)$ most of the load is carried by the threads closest to the free surface (figure 15 ). When the $\mathrm{E}_{\text {screw }} / \mathrm{E}_{\mathrm{hm}}$ ratio is equal to 10 the load appears to be more uniformly distributed over the threads suggesting that an optimum ratio of the screw's elastic modulus over that of its hosting material exists.

The differences between the aforementioned cases can be explained if one considers the deformation of the screw. Figure 18 shows the nodal displacements parallel to the pullout direction along the axis of the screw. As one can see in this figure, when the screw is significantly stiffer than its hosting material $\left(\mathrm{E}_{\text {screw }} / \mathrm{E}_{\mathrm{hm}} \geq 100\right)$ its deformations are very small and it just translates as 
an almost rigid body. Indeed for $\mathrm{E}_{\mathrm{screw}} / \mathrm{E}_{\mathrm{hm}} \geq 100$ the nodal displacements along the screw's axis are almost constant. On the contrary when the screw and its hosting material have comparable elastic moduli they develop comparable deformations. Because of the deformation of the screw the deepest threads translate less compared to the threads which are closer to the free surface. As a result, the deepest threads appear to carry lower load.

As far as the screw's fixation strength is concerned, improving the mechanical "compatibility" between the screw and its hosting material appears to cause a small improvement of the screw's pullout force. More specifically reduction of the $\mathrm{E}_{\text {screw }} / \mathrm{E}_{\mathrm{hm}}$ ration from about 2000 (namely a screw made from a Ti-6Al-4V alloy inserted into a SRPF block with density equal to $0.16 \mathrm{gr} / \mathrm{cm}^{3}$ ) to 10 resulted to only $4 \%$ increase of the respective pullout force.

\section{Discussion and conclusions}

In the frame of the present study a previously developed FE model (Chatzistergos et al., 2010a) was properly modified to investigate the impact of the synthetic bone's material properties and of the "screw - hosting material" relative deformability on the pullout behaviour and mechanical response of the system. 
One of the main features of the aforementioned FE model (Chatzistergos et al., 2010a) of the "screw- hosting material" complex is the accurate simulation of the hosting material failure. For this purpose the elements which lay in the vicinity of the screw were connected to each other using bonded contact elements. The mechanical behaviour of these elements was controlled by the cohesive zone material model (Alfano and Crisfield, 2001) according to which debonding of neighbouring elements occurs when the tangential stress at the interface between these elements reaches the respective shear failure stress of the hosting material. This FE model was designed and validated to simulate the pullout behaviour of a rigid screw pulled out from a SRPF block with material properties similar to those of osteoporotic bone $\left(\mathrm{SRPF}\right.$ density $\left.=0.16 \mathrm{gr} / \mathrm{cm}^{3}\right)$. In order to expand its application range to include cases where the screw and its hosting material have similar stiffness the model of the rigid screw was here replaced by an elastic one.

The modified FE model was validated based on experimental data which obtained in the frame of the present study for cases where the CDH7.5 and CDH6.5 screws were pulled out from SRPF blocks with material properties similar to those of "strong" bone (SRPF density $\left.=0.48 \mathrm{gr} / \mathrm{cm}^{3}\right)$. Experimental data produced in the context of a previous (Chatzistergos et al., 2010a) study for 
the case where the same pedicle screws are pulled out of SRPF blocks with material properties similar to "weak" osteoporotic cancellous bone were also used. The comparison between experimental and numerical results indicated that the modified FE model can predict with a satisfactory accuracy (4.5\%) the pullout force of a pedicle screw inserted into SRPFs with different densities.

The modified FE model was first employed to investigate the impact of SRPF material properties on the screw's pullout force. The results indicated that the pullout force increases linearly with increasing shear yield strength of the SRPF. This conclusion is in agreement with existing literature (Chapman et al., 1996).

As a next step the impact of the screw - hosting material relative deformability was investigated. The results indicated that when the screw and its hosting material have comparable moduli of elasticity $\left(\mathrm{E}_{\mathrm{screw}} / \mathrm{E}_{\mathrm{hm}}<10\right)$ such as in the case of titanium threaded bars inserted into marble, most of the pullout load is carried by the outermost threads and therefore the hosting material in the vicinity of these threads is more likely to fail first (figures 16, 17). On the contrary, for the case where the screw is significantly stiffer compared to its hosting material $\left(\mathrm{E}_{\text {screw }} / \mathrm{E}_{\mathrm{hm}} \geq 100\right)$, such as in the case of metallic orthopaedic screws inserted into cancellous bone, most of the load is carried by the deepest threads (figures 
$12,13)$. In addition the analysis revealed that there is an optimum ratio between the modulus of elasticity of the screw and the respective one of its hosting material, for which the stresses are almost uniformly distributed along the axis of the screws thus improving the mechanical "compatibility" between the screw and its hosting material (figures 14, 15).

Even though improving the mechanical "compatibility" of the screw to its hosting material appears to have a small impact to the screw's pullout force (decreasing of the $\mathrm{E}_{\mathrm{screw}} / \mathrm{E}_{\mathrm{hm}}$ ratio by two orders of magnitude increased the pullout force by $4 \%$ ), in the case of bone screws it could significantly improve its long term efficiency (and eventually longevity) since bone remodelling around orthopaedic implants is greatly influenced by the intensity and the uniformity of the stress field in the vicinity of the implant (Gefen, 2002, Van Rietbergen et al., 1993). It can be appreciated that this observation is in accordance with research objectives aiming at introducing $\beta$-phase implantable titanium alloys of lower moduli (Davis and ASM International., 2003). 


\section{References:}

ALFANO, G. \& CRISFIELD, M. A. 2001. Finite element interface models for the delamination analysis of laminated composites: Mechanical and computational issues. International Journal for Numerical Methods in Engineering, 50, 1701-1736.

ANSYS ANSYS 11.0 Release Documentation. Canonsburg, PA,USA: ANSYS Inc.

CHAPMAN, J. R., HARRINGTON, R. M., LEE, K. M., ANDERSON, P. A., TENCER, A. F. \& KOWALSKI, D. 1996. Factors affecting the pullout strength of cancellous bone screws. J Biomech Eng, 118, 391-8.

CHATZISTERGOS, P. E., MAGNISSALIS, E. A. \& KOURKOULIS, S. K. 2010a. A parametric study of cylindrical pedicle screw design implications on the pullout performance using an experimentally validated finite-element model. Med Eng Phys, 32, 145-54.

CHATZISTERGOS, P. E., SAPKAS, G. \& KOURKOULIS, S. K. 2010b. The influence of the insertion technique on the pullout force of pedicle screws: an experimental study. Spine (Phila Pa 1976), 35, E332-7.

CONRAD, B. P., CORDISTA, A. G., HORODYSKI, M. \& RECHTINE, G. R. 2005. Biomechanical evaluation of the pullout strength of cervical screws. J Spinal Disord Tech, 18, 506-10.

DAVIS, J. R. \& ASM INTERNATIONAL. 2003. Handbook of materials for medical devices, Materials Park, $\mathrm{OH}$, ASM International.

GEFEN, A. 2002. Optimizing the biomechanical compatibility of orthopedic screws for bone fracture fixation. Med Eng Phys, 24, 337-47.

INCEOGLU, S., KILINCER, C. \& MCLAIN, R. F. 2008. Screw design alters the effects of stress relaxation on pullout. Biomed Mater Eng, 18, 53-60.

KORANYI, E., BOWMAN, C. E., KNECHT, C. D. \& JANSSEN, M. 1970. Holding power of orthopedic screws in bone. Clin Orthop Relat Res, 72, 283-6.

KOURKOULIS, S., PAPANICOLOPULOS, S. A., MARINELLI, A. \& VAYAS, I. 2008. Restoration of antique temples: Experimental investigations on the pull-out behaviour of anchors in marble. Bautechnik, 85, 109-119.

KRENN, M. H., PIOTROWSKI, W. P., PENZKOFER, R. \& AUGAT, P. 2008. Influence of thread design on pedicle screw fixation. Laboratory investigation. J Neurosurg Spine, 9, 90-5. 
LONG, M. \& RACK, H. J. 1998. Titanium alloys in total joint replacement--a materials science perspective. Biomaterials, 19, 1621-39.

OKUDA, S., MIYAUCHI, A., ODA, T., HAKU, T., YAMAMOTO, T. \& IWASAKI, M. 2006. Surgical complications of posterior lumbar interbody fusion with total facetectomy in 251 patients. J Neurosurg Spine, 4, 304-9.

REITMAN, C. A., NGUYEN, L. \& FOGEL, G. R. 2004. Biomechanical evaluation of relationship of screw pullout strength, insertional torque, and bone mineral density in the cervical spine. J Spinal Disord Tech, 17, 306-11.

TAFRESHI, A. \& DOVER, W. D. 1993. Stress-Analysis of Drillstring Threaded Connections Using the Finite-Element Method. International Journal of Fatigue, 15, 429-438.

VAN RIETBERGEN, B., HUISKES, R., WEINANS, H., SUMNER, D. R., TURNER, T. M. \& GALANTE, J. O. 1993. ESB Research Award 1992. The mechanism of bone remodeling and resorption around press-fitted THA stems. J Biomech, 26, 369-82.

ZHANG, Q. H., TAN, S. H. \& CHOU, S. M. 2004. Investigation of fixation screw pull-out strength on human spine. J Biomech, 37, 479-85.

ZHANG, Q. H., TAN, S. H. \& CHOU, S. M. 2006. Effects of bone materials on the screw pull-out strength in human spine. Med Eng Phys, 28, 795-801.

ZINDRICK, M. R., WILTSE, L. L., WIDELL, E. H., THOMAS, J. C., HOLLAND, W. R., FIELD, B. T. \& SPENCER, C. W. 1986. A biomechanical study of intrapeduncular screw fixation in the lumbosacral spine. Clin Orthop Relat Res, 99-112. 


\section{Tables:}

Table 1 The mechanical properties of the synthetic bone used for the realization of the pullout tests and the respective properties for a typical Ti-alloy used for manufacturing medical devices (Long and Rack, 1998).

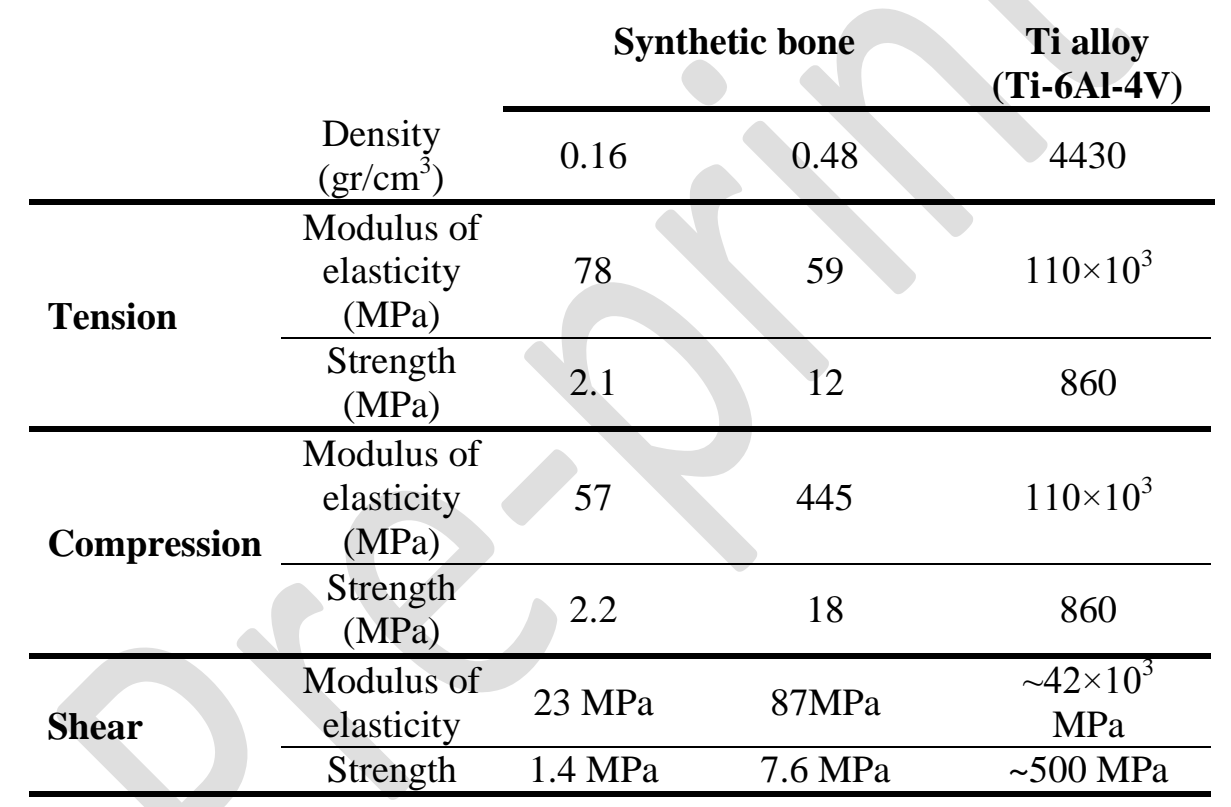


Table 2 The values of the quantities used to define thread geometry

\begin{tabular}{|c|c|c|c|}
\hline & $\begin{array}{l}\text { Screw } \\
\text { type: }\end{array}$ & \multirow[t]{2}{*}{$\begin{array}{c}\text { CDH } \\
6.5\end{array}$} & \multirow[t]{2}{*}{$\begin{array}{c}\text { CDH } \\
7.5\end{array}$} \\
\hline Quantity & Units & & \\
\hline Outer radius (OR) & $\mathrm{mm}$ & 3.25 & 3.75 \\
\hline Core radius (CR) & $\mathrm{mm}$ & 2.25 & 2.75 \\
\hline Thread depth (D) & $\mathrm{mm}$ & & \\
\hline $\begin{array}{l}\text { Thread inclination } \\
\text { angles }\left(a_{1}, a_{2}\right)\end{array}$ & deg & & \\
\hline Pitch (P) & $\mathrm{mm}$ & & \\
\hline Thread thickness (e) & $\mathrm{mm}$ & & \\
\hline Curvature radii (R1, R2) & $\mathrm{mm}$ & & \\
\hline
\end{tabular}


Table 3 The properties of the SRPFs blocks used in the study.

\begin{tabular}{cccc}
\cline { 2 - 4 } & \multicolumn{2}{c}{ Compressive } & Shear \\
\hline $\begin{array}{c}\text { Density } \\
\left(\mathrm{gr} / \mathrm{cm}^{3}\right)\end{array}$ & $\begin{array}{c}\text { Strength } \\
(\mathrm{MPa})\end{array}$ & $\begin{array}{c}\text { Modulus } \\
(\mathrm{MPa})\end{array}$ & $\begin{array}{c}\text { Strength } \\
(\mathrm{MPa})\end{array}$ \\
\hline 0.08 & 0.6 & 16 & 0.59 \\
\hline 0.16 & 2.2 & 58 & 1.6 \\
\hline 0.24 & 4.9 & 123 & 2.8 \\
\hline 0.32 & 8.4 & 210 & 4.3 \\
\hline 0.4 & 12.9 & 317 & 5.9 \\
\hline 0.48 & 18 & 445 & 7.6 \\
\hline 0.64 & 31 & 759 & 11 \\
\hline 0.8 & 48 & 1148 & 16 \\
\hline
\end{tabular}


Author

\section{Figure captions:}

Figure 1 The experimental set-up

Figure 2 The pedicle screws used for the experimental study. CD Horizon 7.5 (up) and CD Horizon 6.5 (down)

Figure 3 The central section of an SRPF block after the completion of a pullout test

Figure 4 The geometry of the screw's FE model. OR: Outer radius, CR: Core radius, P: Pitch, D: Thread depth, $\mathrm{R}_{1,2}$ : Curvature radii, e: Thread thickness, $\mathrm{a}_{1,2}$ : Thread inclination

Figure 5 The geometry of the FE model of the screw hosting material. The model is divided into two areas (i) and (ii). Mode-II debonding of neighbouring elements is possible only in area (i)

Figure 6 The FE model of the "screw - hosting material" complex and the boundary conditions imposed to simulate the pullout phenomenon 
Figure 7 The experimentally measured and the numerically calculated pullout force for the CDH7.5 (up) and the CDH6.5 (down) screws for the cases where they are inserted into SRPF blocks of densities equal to $0.16 \mathrm{gr} / \mathrm{cm}^{3}$ and $0.48 \mathrm{gr} / \mathrm{cm}^{3}$, respectively

Figure 8 The force/displacement curve obtained when the CDH7.5 screw is pulled out from an SRPF block of density equal to $0.8 \mathrm{gr} / \mathrm{cm}^{3}$

Figure 9 The distribution of the von Mises equivalent stress ( $\mathrm{Pa})$ into the synthetic bone of density equal to $0.8 \mathrm{gr} / \mathrm{cm}^{3}$ (up) and the CDH7.5 screw (down) when the screw is pulled $0.1 \mathrm{~mm}$ out from its hosting material

Figure 10 The distribution of the von Mises equivalent stress (Pa) into the synthetic bone of density equal to $0.8 \mathrm{gr} / \mathrm{cm}^{3}$ (up) and the CDH7.5 screw (down) when the screw is pulled $4.5 \mathrm{~mm}$ out from its hosting material

Figure 11 The pullout forces of the CDH7.5 and the CDH6.5 screws calculated for SRPF blocks of different shear yield stresses. 
Figure 12 The von Mises equivalent stress (Pa) distribution into the synthetic bone for $\mathrm{E}_{\text {screw }} / \mathrm{E}_{\mathrm{hm}}$ ratio equal to 100 and for two different load steps: (A) for a displacement corresponding to half of the maximum sustained force, (B) for a displacement corresponding to the maximum sustained force

Figure 13 The parallel to the pullout direction forces carried by each thread of the screw at two different load steps (see figure 12) when the $\mathrm{E}_{\mathrm{screw}} / \mathrm{E}_{\mathrm{hm}}$ ratio is equal to 100. Thread numbering begins from the SRPF block's free surface

Figure 14 The von Mises equivalent stress (Pa) distribution into the synthetic bone for $\mathrm{E}_{\mathrm{screw}} / \mathrm{E}_{\mathrm{hm}}$ ratio equal to 10 and for two different load steps: (A) for a displacement corresponding to half of the maximum sustained force, (B) for a displacement corresponding to the maximum sustained force

Figure 15 The parallel to the pullout direction forces carried by each thread of the screw at two different load steps (see figure 14) when the $\mathrm{E}_{\mathrm{screw}} / \mathrm{E}_{\mathrm{hm}}$ ratio is equal to 10. Thread numbering begins from the SRPF block's free surface 
Figure 16 The von Mises equivalent stress $(\mathrm{Pa})$ distribution into the synthetic bone for $\mathrm{E}_{\text {screw }} / \mathrm{E}_{\mathrm{hm}}$ ratio equal to 1 and for two different load steps:

(A) for a displacement corresponding to half of the maximum sustained force,

(B) for a displacement corresponding to the maximum sustained force

Figure 17 The parallel to the pullout direction forces carried by each thread of the screw at two different load steps (see figure 16) when the $\mathrm{E}_{\mathrm{screw}} / \mathrm{E}_{\mathrm{hm}}$ ratio is equal to 1 . Thread numbering begins from the SRPF block's free surface

Figure 18 The distribution of the nodal displacements along the axis of the screw for cases of different relative screw - hosting material stiffness. The displacements are normalized over their maximum value 


\section{Figures:}

Figure 1.

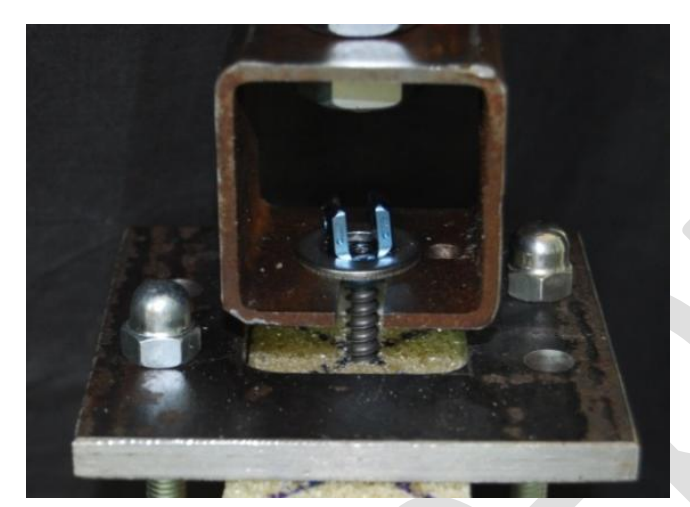


Figure 2.

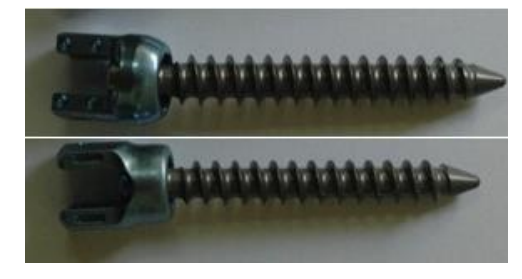


Figure 3.

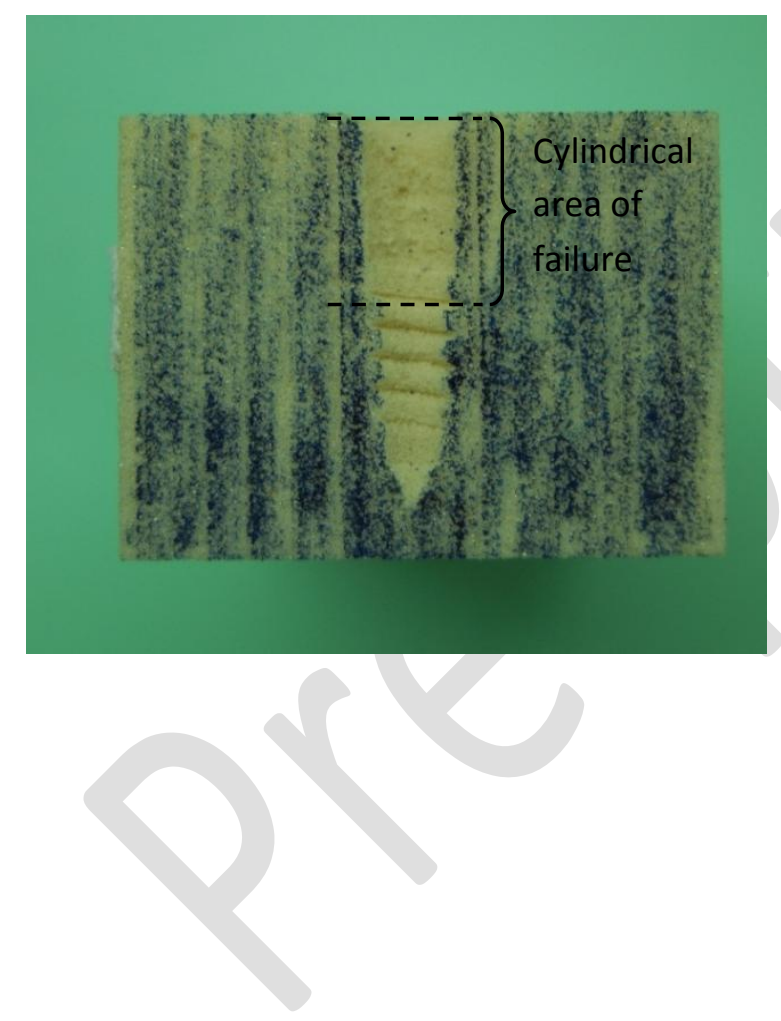


Figure 4.

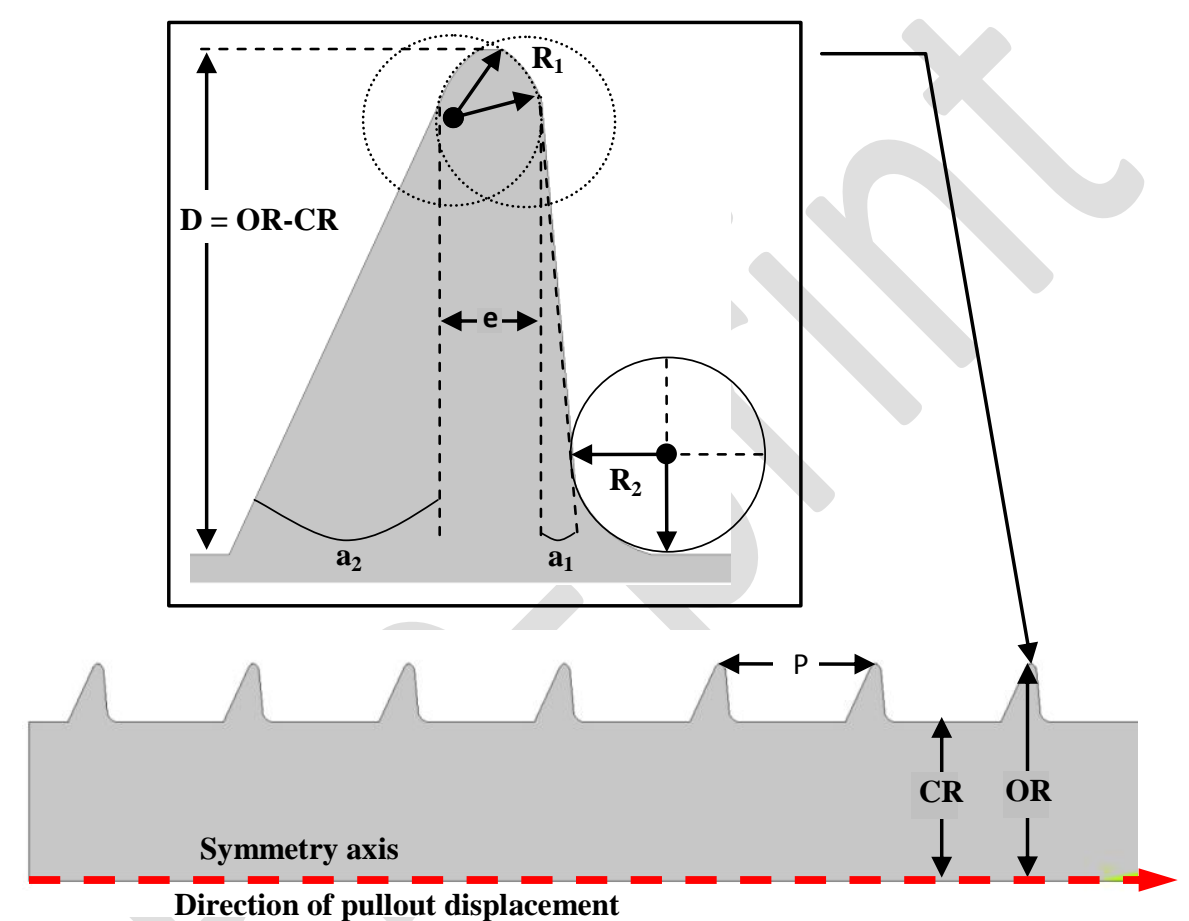


Figure 5.

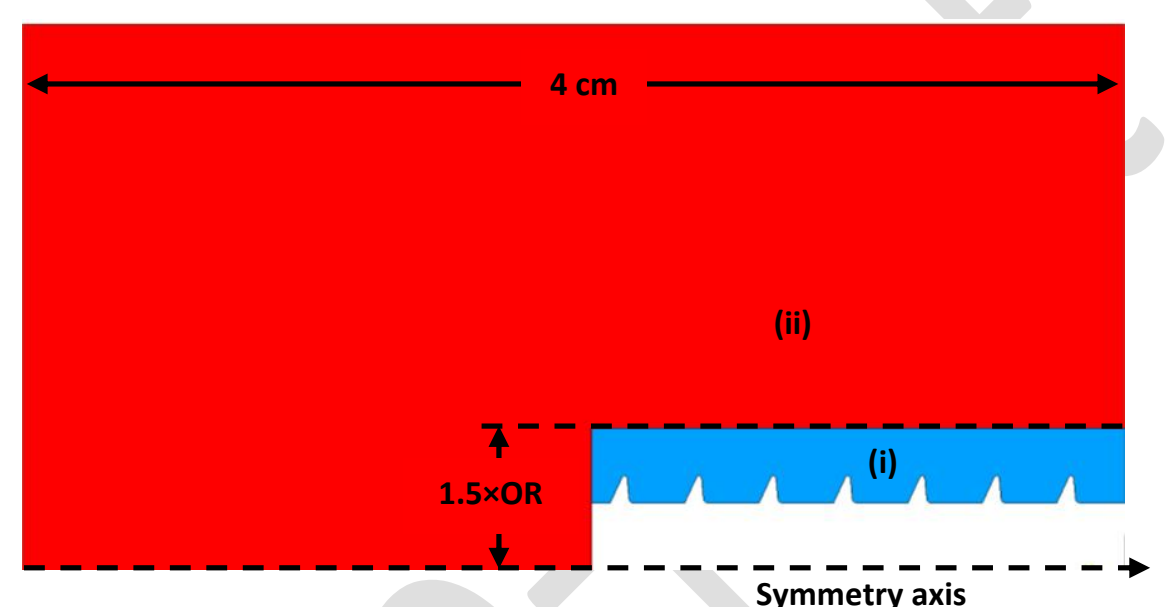

Symmetry axis 
Figure 6.

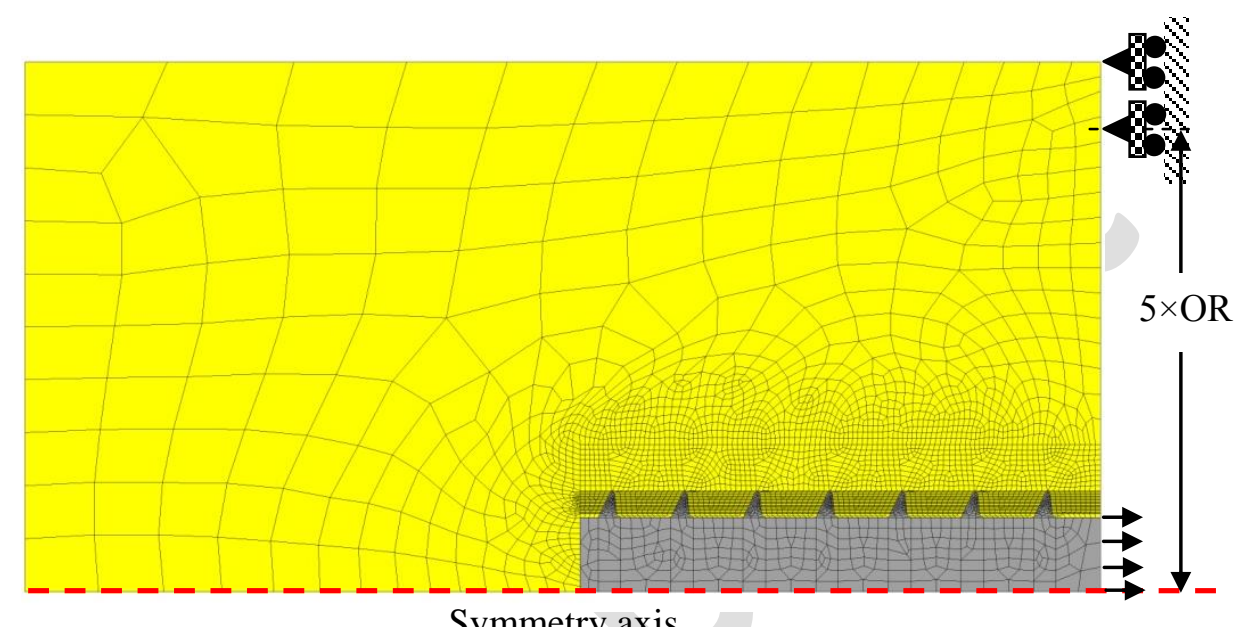

Symmetry axis 
Figure 7.
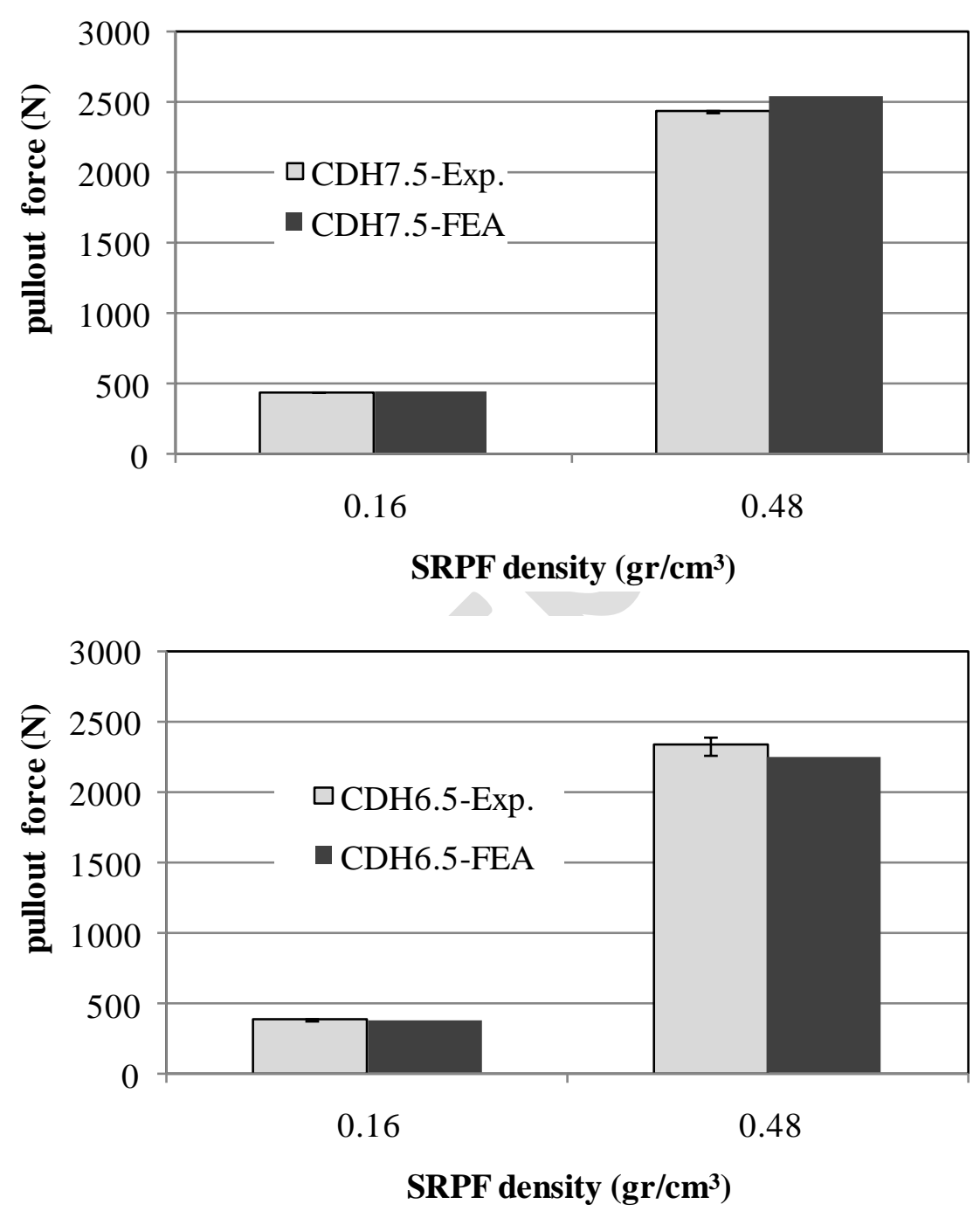
Figure 8.

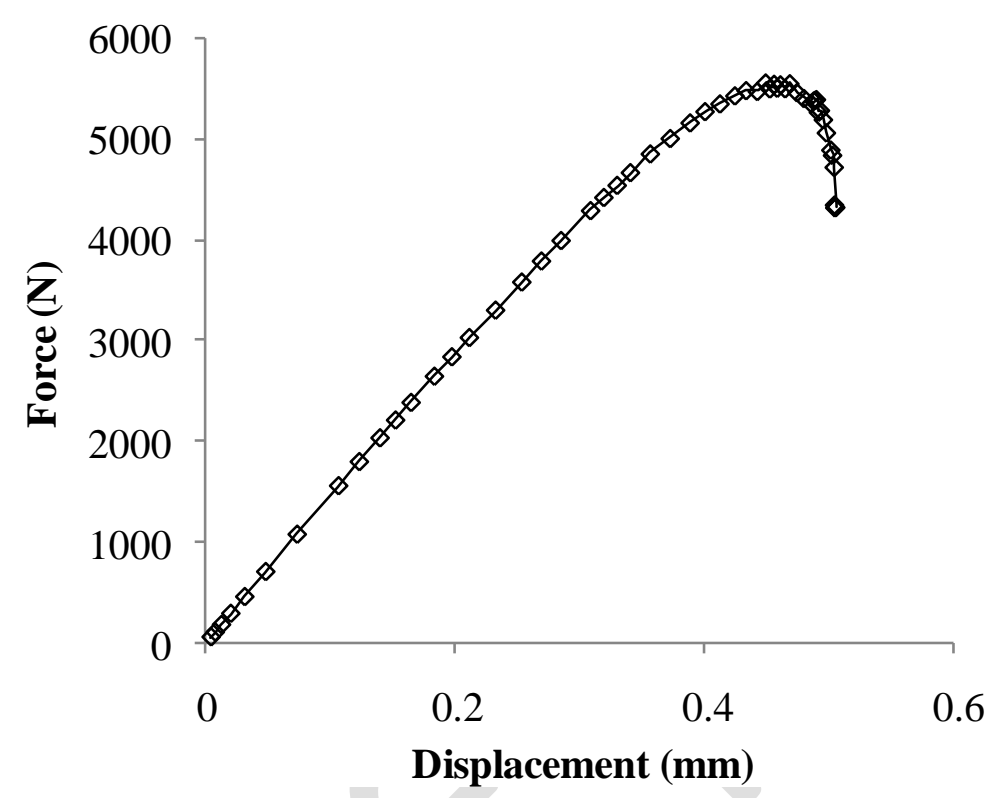


Figure 9.
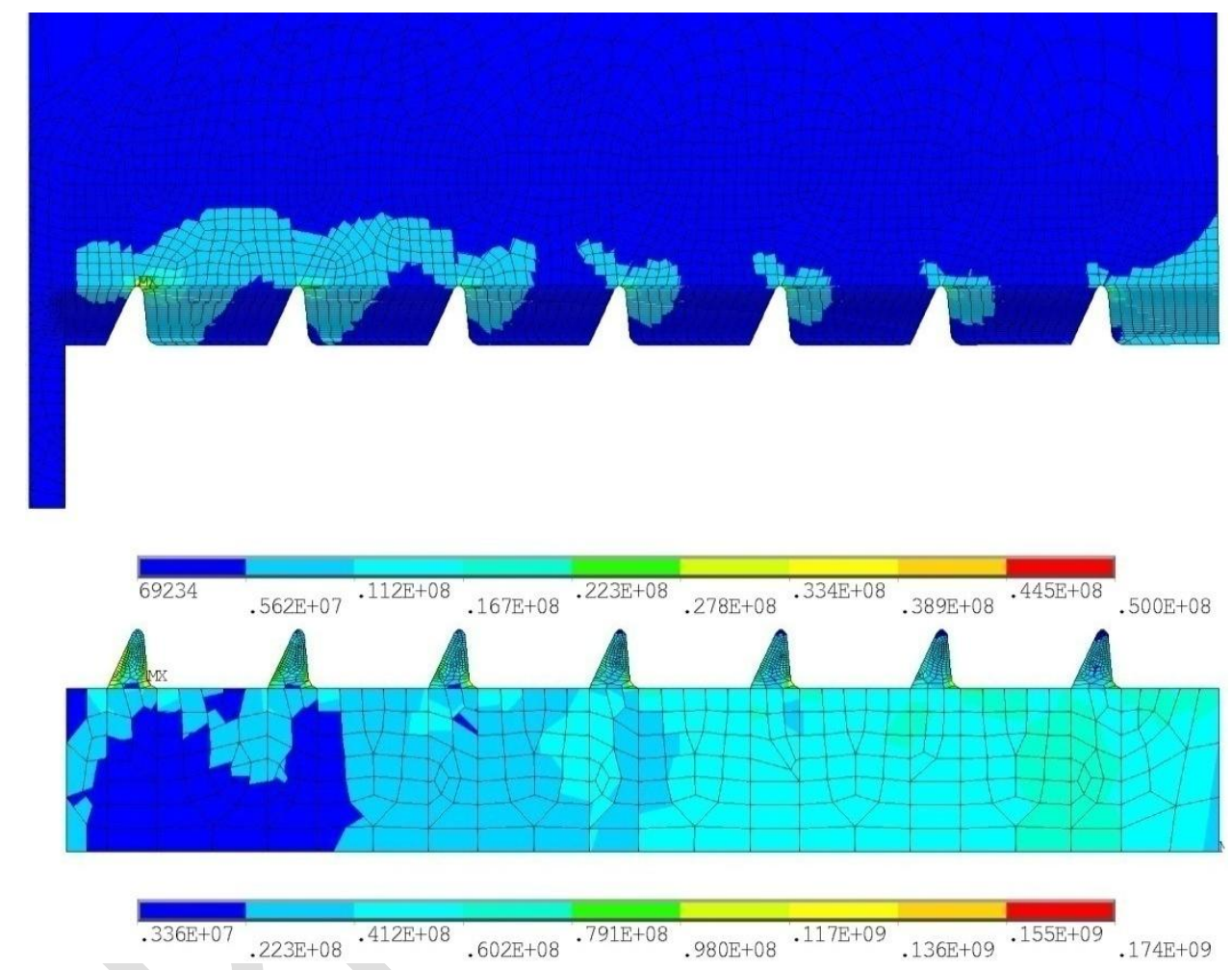
Figure 10.
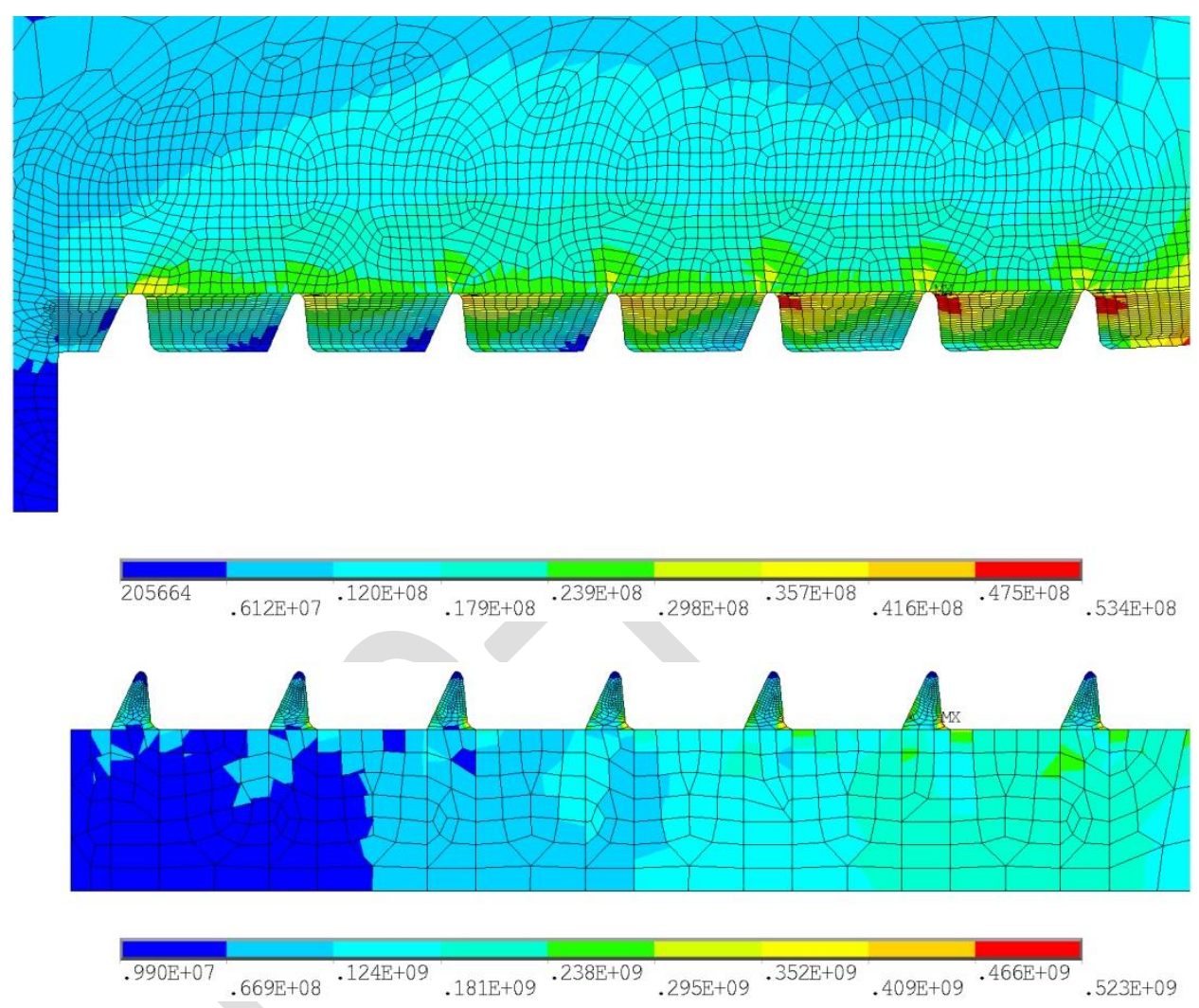


\section{Author}

Figure 11.

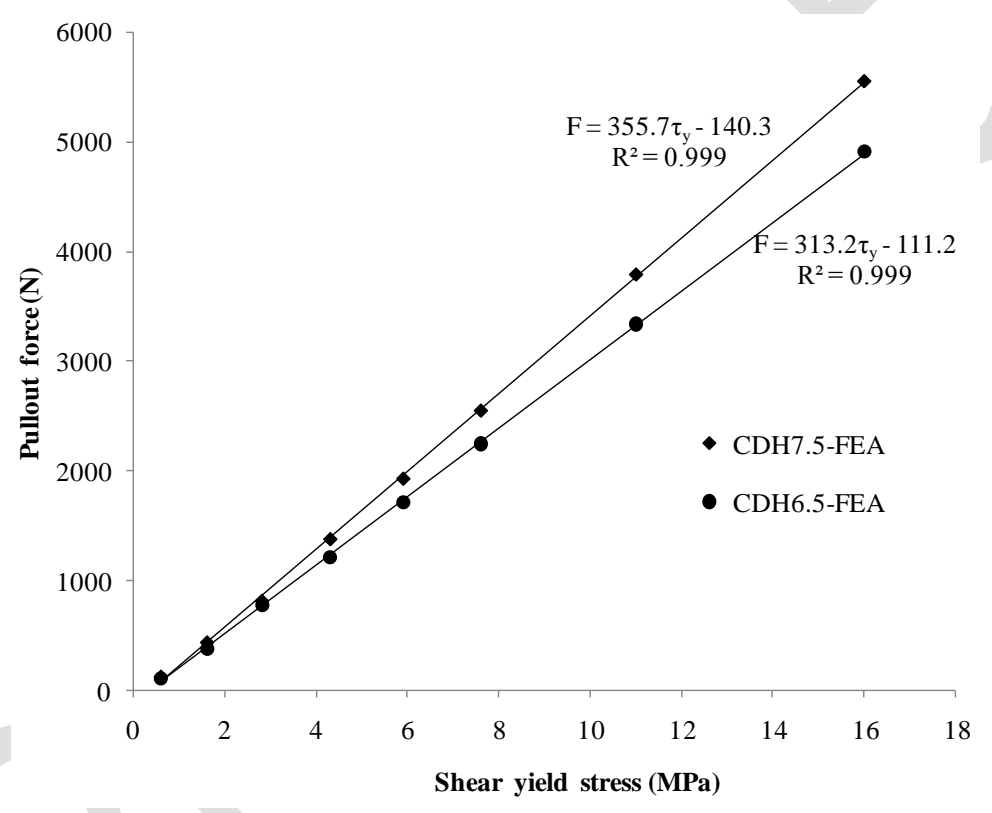


Figure 12.

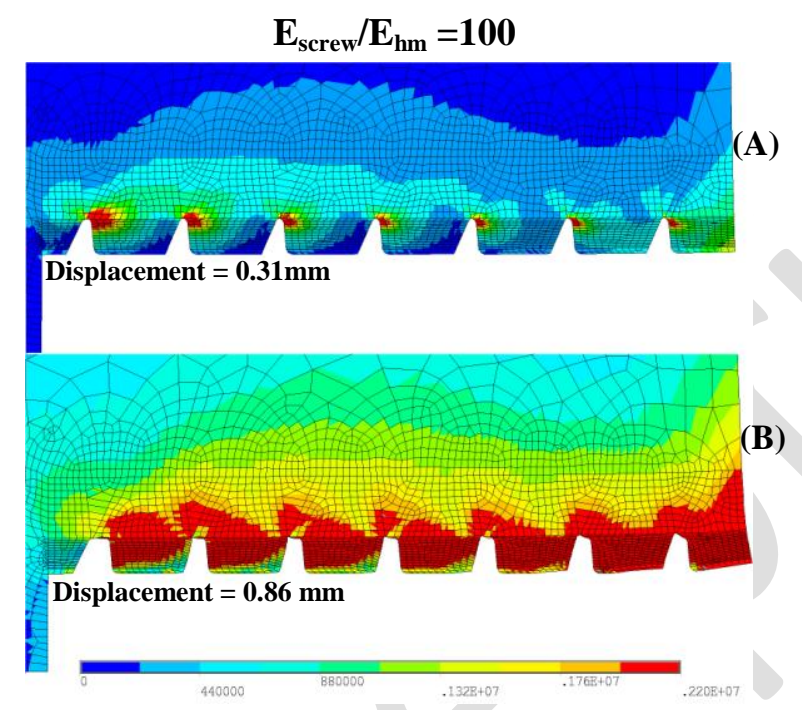


Figure 13.

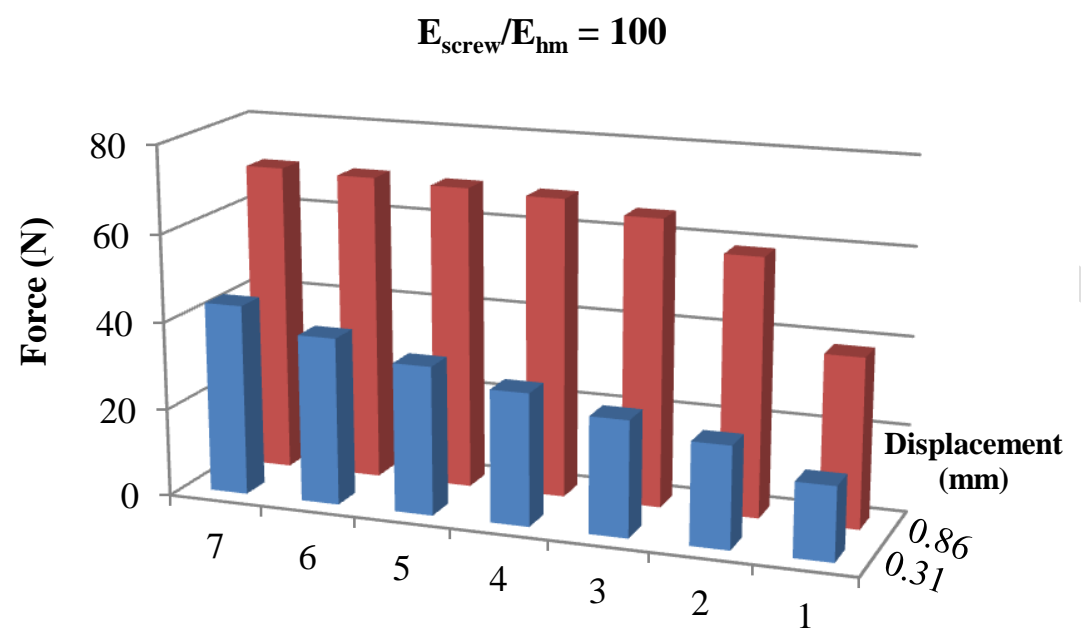

Number of thread 
Figure 14.

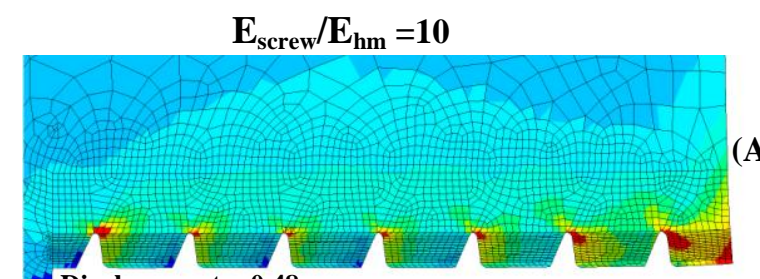

(A)

Displacement $=0.48 \mathrm{~mm}$

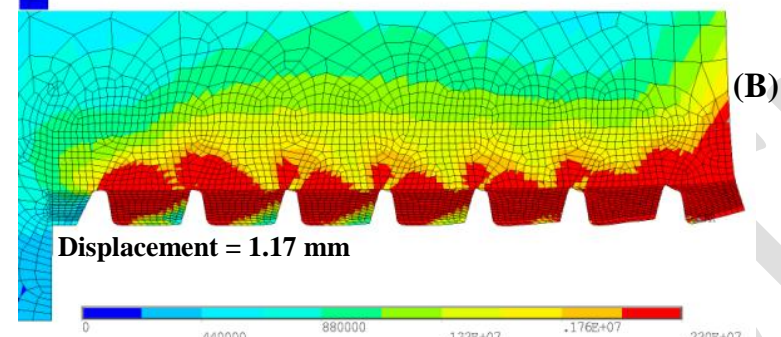




\section{Author}

Figure 15.

$$
\mathbf{E}_{\text {screw }} / \mathbf{E}_{\mathrm{hm}}=\mathbf{1 0}
$$

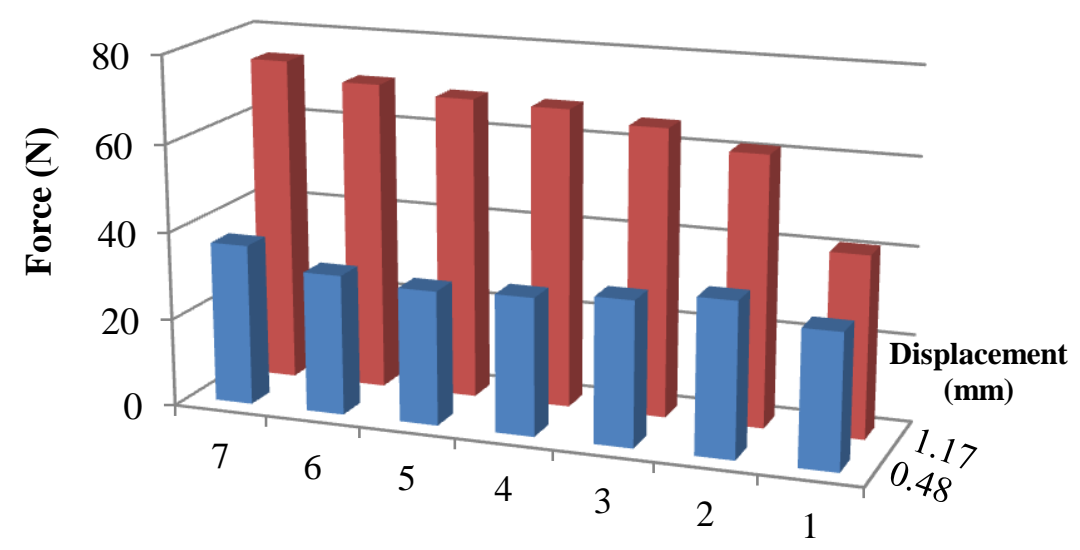

Number of thread 
Figure 16.

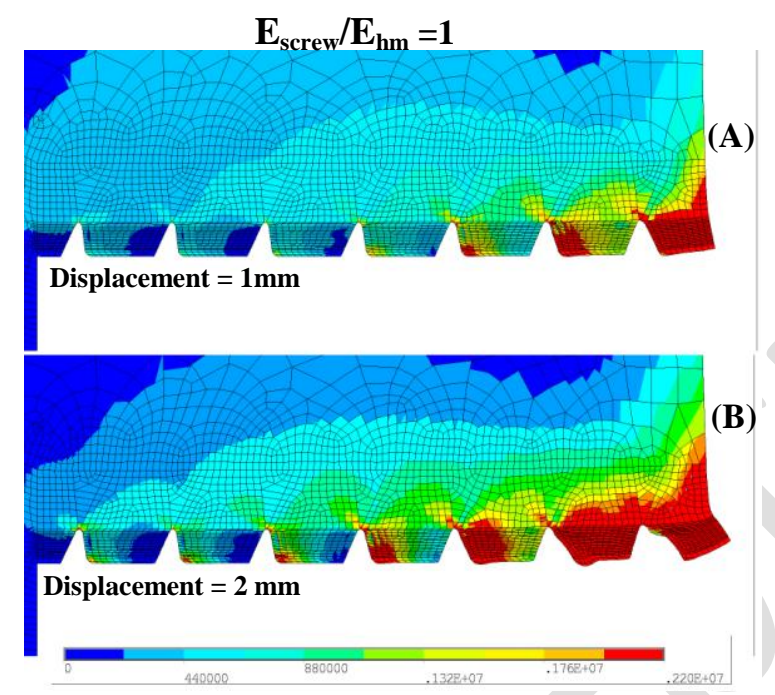




\section{Author}

Figure 17.

$$
\mathbf{E}_{\text {screw }} / \mathbf{E}_{\mathrm{hm}}=\mathbf{1}
$$

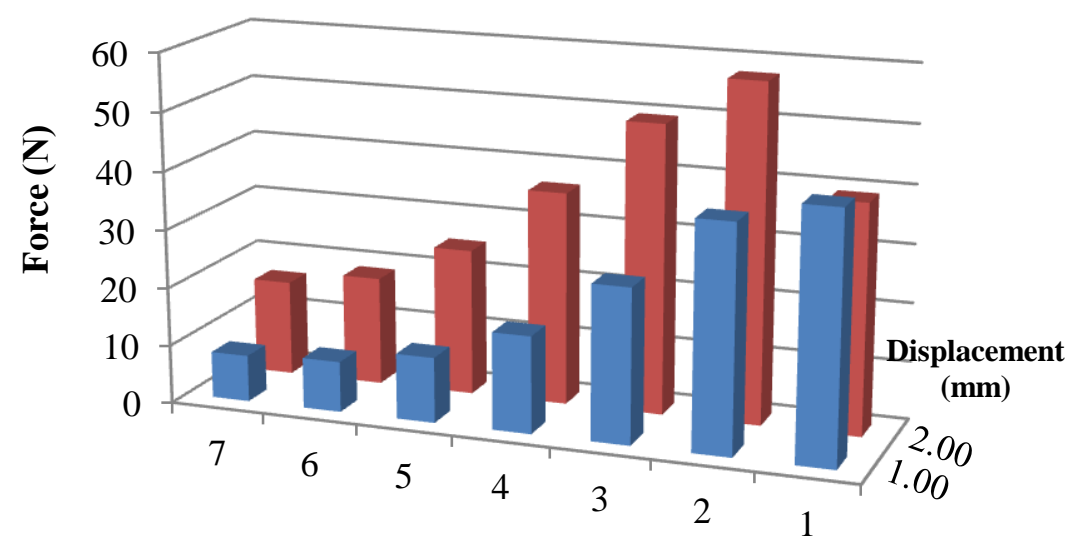

Number of thread 
Figure 18.

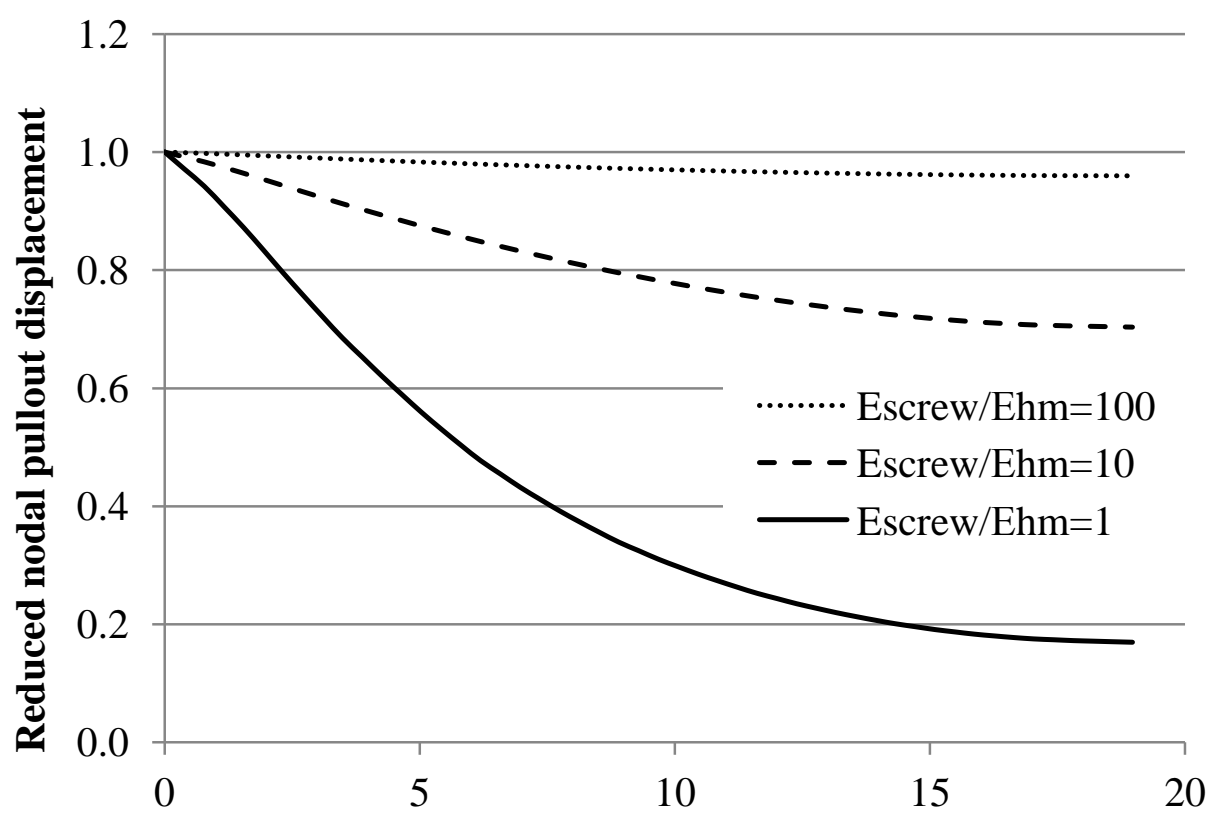

Distance along the longitudinal axis of the screw (mm) 